\title{
Designing for Degrowth: Architecture Against Climate Apartheid
}

\author{
SASHA PLOTNIKOVA \\ Independent Scholar
}

Keywords: degrowth, social justice, environmental justice, gentrification, green-washing

This paper challenges architects to consider a political economy that allows for social and ecological sustainability in the practice of architecture. At a time that bears witness to scores of radical proposals for re-shaping the field, we have the opportunity to reconsider the foundations of the field, and to pinpoint systemic injustices in which the building industries are complicit. In engaging a conversation about alternatives to a market-driven design field, this paper opens up a conversation about the ethics of sustainable design as it's been practiced under the prevailing growth-driven economic model, in comparison with how it might fortify the longevity of a community under an alternative framework. The paper will point to examples of existing practices that apply principles of degrowth in furthering sustainable building and living practices in the context of their community. Using the framework of degrowth, this paper expands the notion of sustainable design to include the social dimension (ie, whether a project sustains a community or displaces it); provides an analysis of "green growth" and "green-washing," and equips architects with an understanding of ecology that considers the biosphere and the community where the project is sited as being inextricable from one another.

\section{WHY GROWTH?}

The past few years have brought about a wave of radical proposals in the field of architecture. The proposals-be they written manifestoes, prototypes for a new era of architecture education, or design projects - emerge from a generation of designers, educators, and students who recognize that we are overdue for a reckoning with the inequalities perpetuated within and by the practice of architecture. This moment of reflection gives us the opportunity to reconsider the foundations of the field, and to pinpoint systemic injustices in which the building industries are complicit.

Challenging architecture's allegiance to economic growth must be at the center of any project to make the field more just. Under a growth-driven economy, architecture has blindly served to better the lives of the already wealthy, while giving form to the forces that immiserate marginalized communities the world over. Despite ecological and social boundaries to growth becoming more vivid as wildfires rage, ice sheets melt, and the US stares down an eviction crisis, the field of architecture has yet to question the political economy that has come to define architectural design as an integral part of the growth machine. Meanwhile, this growth-centered political economy has only limited our imaginations and our potential as designers. Most importantly, a growth economy has weaponized the majority of architectural activity performed today, against immigrant, low-income, and BIPOC (Black, Indigenous, and people of color) communities.

\footnotetext{
"I am not proposing a return to the Stone Age. My intent is not reactionary, nor even conservative, but simply subversive. It seems that the utopian imagination is trapped, like capitalism and industrialism and the human population, in a one-way future consisting only of growth. All I'm trying to do is figure out how to put a pig on the tracks."

\section{-Ursula K. Le Guin, A Non-Euclidean View of California as a Cold Place to Be}

\section{THE TROUBLE WITH SUSTAINABILITY}

Before we can consider how architecture can challenge the growth-driven framework within which it currently operates, we need to consider how we define ecology. Ecology, or ecological thinking, is pivotal to this discussion because it can be used to foster an understanding of the ways that the social and environmental impacts of a growth economy are intertwined. Ecological thinking takes a holistic approach to conceptualizing the causes, effects, and ways to address our social and environmental problems. If we do away with the notions that nature is "over there," distinct from us; and that individual choices can mount a challenge to environmental and social destruction; it's not hard to see that the way we've conceived of sustainability - that is, growth but green-is woefully inadequate to addressing inequality.

The term "sustainable development" emerged in the 1980s in response to a rising concern among progressive economic theorists about the ecological impact of economic growth and its material effects on lives of people world-wide. At this point, it was becoming clear that the dominant mode of development was further disenfranchising already-marginalized 
communities and destroying ecologies around the globe. These concerns were documented in the Limits to Growth report in $1972^{1}$, which argued that the prevailing economic logic-expansion through resource extraction - would become increasingly destructive, and eventually, impossible, on a planet with finite resources.

Unfortunately, the proponents that came to champion and define sustainable development were interested in technomanagerial fixes rather than the systemic, political, or economic overhauls suggested in Limits to Growth. Speakers at the 1992 Earth Summit ${ }^{2}$ put the final nail in the coffin, promoting a notion of sustainability that completely disentangled the environment from economic growth and depoliticized the issue of environmental collapse.

A central pitfall of this apolitical, technologically-oriented sustainability policy-making is what's been called "Jevons paradox." In 1865, English economist William Stanley Jevons observed the contradictory results of efficiency-oriented solutions. ${ }^{3}$ He observed that under capitalism, the more efficiently a resource can be used, the more of it will be used. At the same time, these efficiencies may present themselves as a decreased strain on resources to an individual, while only driving more consumption in the economy as a whole, and more negative impacts on poor communities. Increasing the efficiency of, for example, an HVAC system in a private residence may lower the homeowner's utility bills, but they will use the money they saved to buy new electronics or a flight to a far-away destination. In other words, sustainability logic neglects to address structural issues. By individualizing systemic problems, and offering technical, rather than structural solutions, sustainability only serves to keep current rates of consumption intact.

Sustainable development laid the groundwork for what would be a decades-long cooptation of environmentalism by capitalism. Because of this inherent bias in favor of growth, sustainable design fails to address the widespread social inequality necessitated by a growth-driven system. This approach is quickly becoming ubiquitous in the field of architecture. LEED ratings have climbed to the top of an architect's agenda when executing a project, and environmental sustainability is widely taught in design programs. When architects talk about ecology in relation to their work, they discuss passive energy, graywater systems, and window decals that prevent birds from flying into glass curtainwalls. However, the field has made little progress towards normalizing a concern for social sustainability - the longevity and well-being of marginalized communities. This pattern reflects the pitfalls of sustainability thinking within a growth-oriented framework, and demonstrates that any solutions to environmental problems that maintain growth at their center, are not conceived using ecological thinking. Under green growth, social issues go unchecked. The Global North benefits as the Global South bears the brunt of resource extraction and exploitative labour conditions. Foreign investors, wealthy property owners, and tourists claim more and more space in so-called 'global cities,' at the expense of working-class communities, who are displaced from their neighborhoods to make room for the luxury developments that cater to a global elite. A political economy premised on perpetual economic growth has given us this market-driven approach to urban planning and design, which has deliberately widened the gap between the rich and the poor. Frontline communities - Indigenous groups and the urban working class - have long recognized the need for a complete overhaul in the way that we structure our political economy. But under the current system, even proposals that are considered radical, like the Green New Deal, are limited to technical solutions-leaving the prevailing political economic order intact.

In conversations amongst community organizers, tenants unions, and advocates for the unhoused, the risk of climate apartheid poses a very real and immanent threat. Climate apartheid is a scenario in which those who can afford it, move to climate-proof fortresses, while the rest of the world's population suffers increasing wildfires, deepening droughts, an an entropic degradation of air and water quality. This is already happening, with BIPOC communities showing higher rates of climate crisis-induced health conditions; displacement; food insecurity, and less access to green space and fresh air when compared to predominantly white middle and upper-class neighborhoods. These conditions cannot be undone under a growth-centered, capitalist economy. Capitalism relies on the creation and subjugation of a class of people that shoulder the cost of the betterment of life for the rich.

Greenwashing, which follows the eco-modernist logic that technology can solve problems that technology creates; is a favorite tactic of developers looking to capitalize on land in gentrifying neighborhoods. Greenwashing is a wolf in sheep's clothing: developments and renovations that check many of the boxes of what is widely accepted to be environmentally-responsible design, but meet none of the needs of the community that is already there and has typically suffered from decades of disinvestment. The end product is LEED-certified luxury condos that replace rent-controlled apartments, highend espresso bars in working-class neighbourhoods boasting reclaimed wood and recycled furniture, and zero-waste grocery stores moving in next to mom-'n'-pop green grocers, whose landlords opportunistically raise rent, forcing them to close. This is the built environment under a growth-centered economy. An architecture of displacement, no matter its LEED rating, is fundamentally unsustainable.

Growth is to blame. The issue is not that "we" (who?) are choosing to live beyond our means, but that the capitalist machine is producing and consuming beyond what's needed, and in disregard of what's moral. While we're told that what's hurtling us towards climate collapse is the sum of individualized problems: 


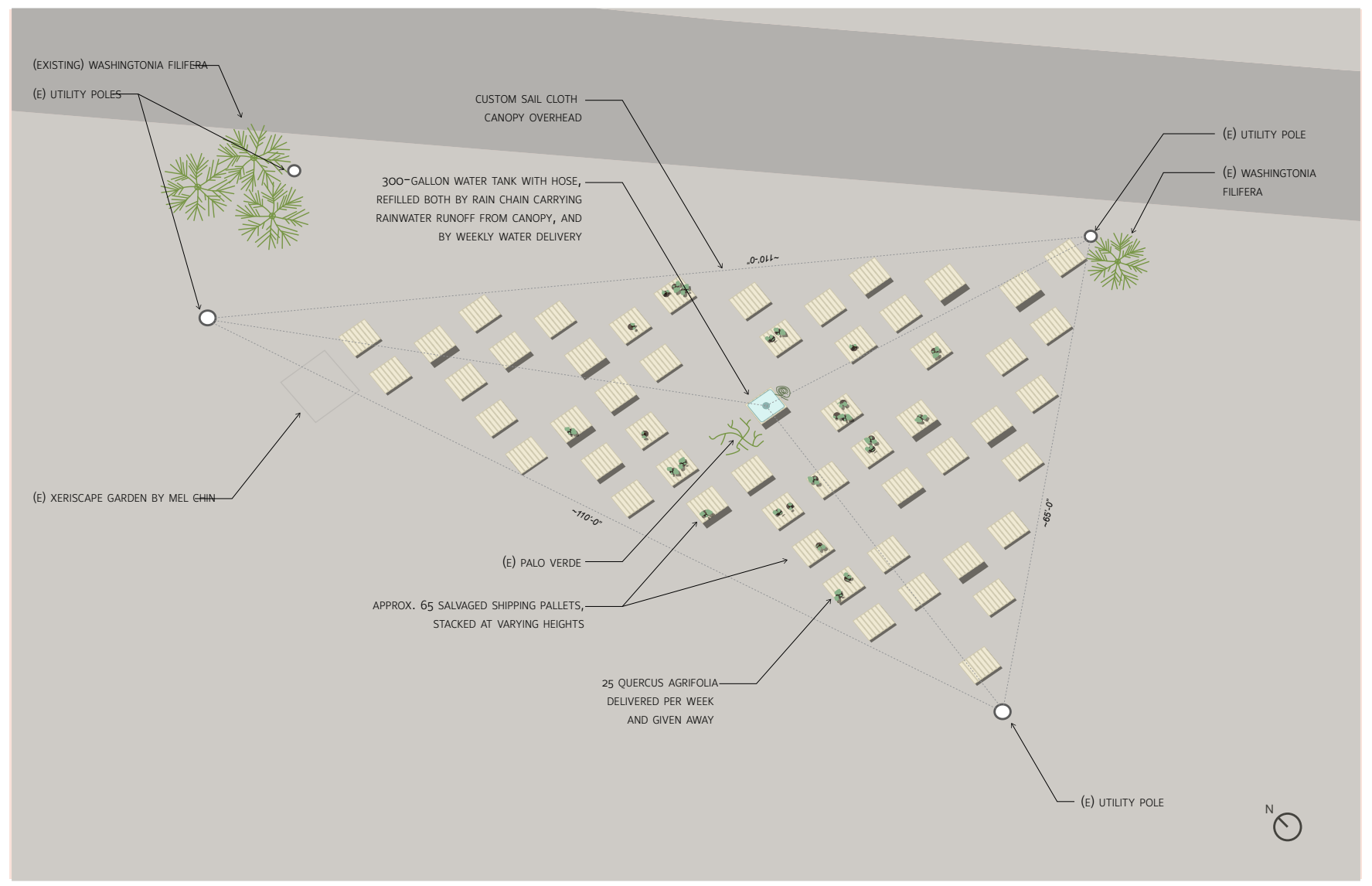

Figure 1. Quercus Supply Unlimited (QSU): plan for a pirate nursery for Northeast LA by OOLA. Image by author.

plastic waste, rainforest destruction, and carbon emissions; growth underlies all of those assaults on the biosphere, while destroying communities and proliferating exploitative labour practices.

\section{DEGROWTH OFFERS AN ALTERNATIVE}

An emerging economic theory offers an alternative to the "grow or die" ultimatum posed by a growth economy. Technological fixes alone will not solve the climate crisis. The environmental crisis is not a crisis of method-of efficiency and technology - but one of social and ecological limits. The solution will lie in developed nations recognizing existing limits and volunteering new bounds to their own production and consumption: degrowth. Degrowth offers a vocabulary that gravitates around the concepts of limits, care, and democracy, rather than offering a blueprint like many conventional economic theories do. ${ }^{4}$ Its name is a provocation: Why do we think of growth as inherently good? How does likening an economic process to a natural one neutralize its impacts, and naturalize its political agenda? Degrowth scholars intend to ignite local and global conversations about the redistribution of resources, and about the possibility of developed economies intentionally scaling back to give ecological space for marginalized communities to thrive.
The environmental crisis cannot begin to be addressed without an anticapitalist analysis of its causes and effects. Environmental justice is contingent on the redistribution proposed by many degrowth advocates. Degrowth suggests that a carefully programmed decline in production and consumption would correlate with an incline in quality of life ${ }^{5}$, starting with those for whom living conditions are the worst now. Capitalism tells us to worry that resources are running out, while neoliberalism moralizes that we (again, who?) are each consuming too much. While elements of both arguments are true, they lack an analysis of power. With an internationalist lens, degrowth recognizes the necessarily uneven development of the world under capitalism and suggests a framework by which the most impacted communities could determine their own growth.

A degrowth program starts with local and global reforms. Globally, developed countries would engage in a co-ordinated effort to strictly cap their own carbon emissions and provide aid to the Global South. Locally, there would be changes to financial institutions, a moratorium on luxury development; reduced working hours, and universal basic income paired with an increased social safety net. In the meantime, there would be investment in community-controlled institutions: co-ops, eco-villages, community farms, and retrofits to vacant buildings to provide low-income or public housing. Today, 
prefigurations of a world without economic growth are all around us, within the cracks of the growth-driven system, in communal kitchens, urban farms, and childcare cooperatives.

\section{ARCHITECTURE WITHOUT GROWTH}

An economy propelled by extractivism has diminished the role of architecture to a luxury service - a tool with which to raise land values, or a weapon of real estate waged by the wealthy against the poor. Gentrification is destroying cities, but architects have an opportunity to counter this process, and to prioritize community resilience in their work instead. In what Samuel Stein has called "the real estate state" ${ }^{\text {" in US }}$ cities, the right to the city has been seized by Big Real Estate. In a sustainable world, this right-the right to safe, stable and affordable housing; the right to an enduring community; and the right to true participation in municipal governance and budgeting - would belong to low-income communities and communities of colour, not real estate corporations. As a result of growth-centered architecture, American cities are in a crisis of tenancy (what many mistakenly call a crisis of "housing"), an eviction epidemic that dates much further back than the COVID-19-induced crisis, and an assault on the longevity of communities, all triggered by the dogma of growth. This is gentrification, as defined by the Los Angeles Tenants Union: the displacement and replacement of the poor for profit. ${ }^{7}$

For architects to practice environmental justice, the transition that we promote must be a just transition for all. To truly consider the problems caused by our growth-centered approach ecologically would require considering the relations and mutual impacts between architectural activity, an existing community, and the biosphere. A healthy design ecology is a situation in which an act of design ensures the longevity of the existing community.

Reconnecting the ecological and the social, degrowth repoliticizes environmentalism. As similar efforts to re-engage political debates emerge within the field of architecture, architects cannot let the political economy go unchallenged. What might an architecture of living within our means look like? What is an architecture that does away with 'grow or die'? How does architecture practice sufficiency, rather than efficiency? Challenging the economic foundations of the field will impact the practice of architecture at all levels.

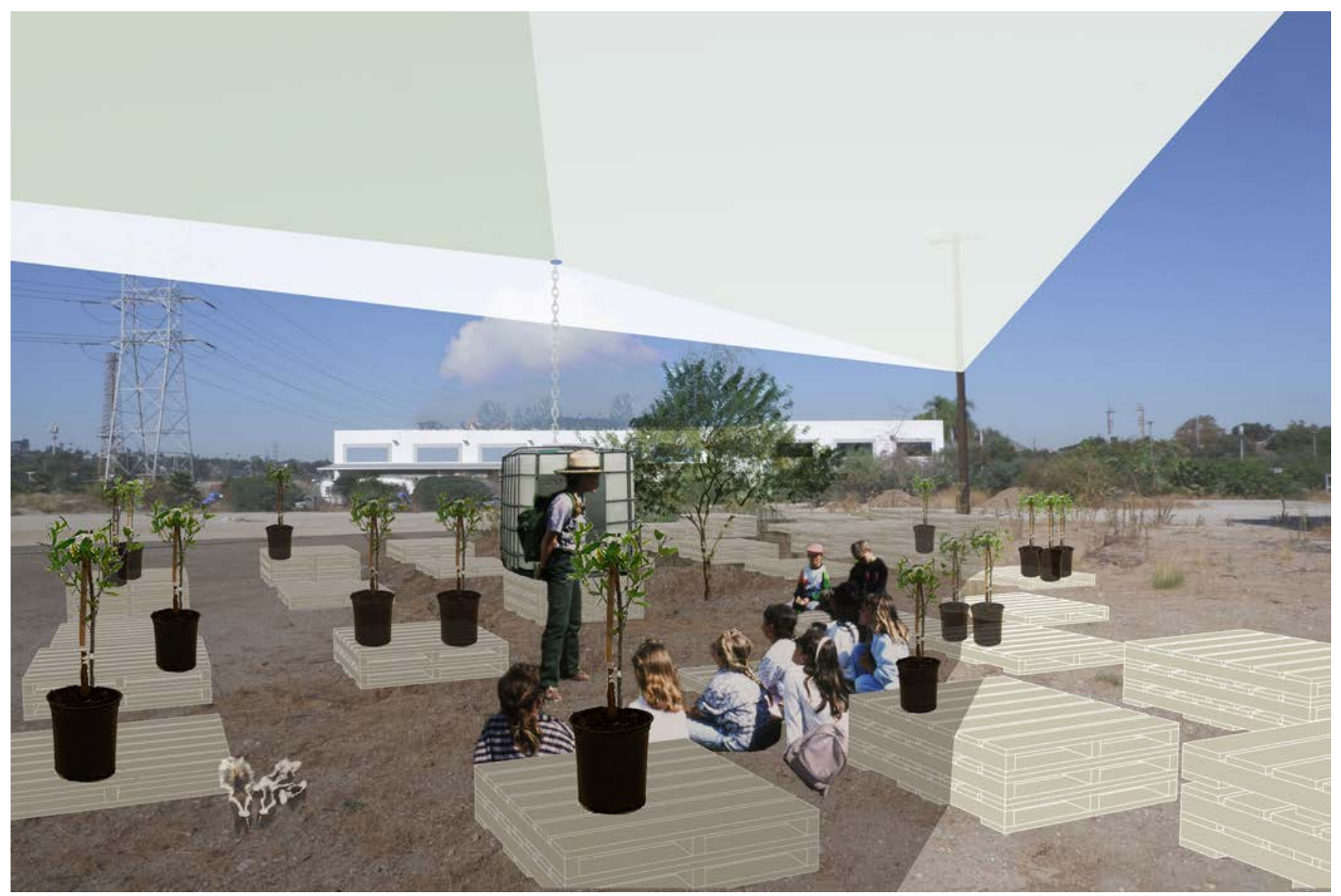

Figure 2. QSU: Kids get a lesson about their local ecology from a park ranger under the shade canopy. Image by author. 


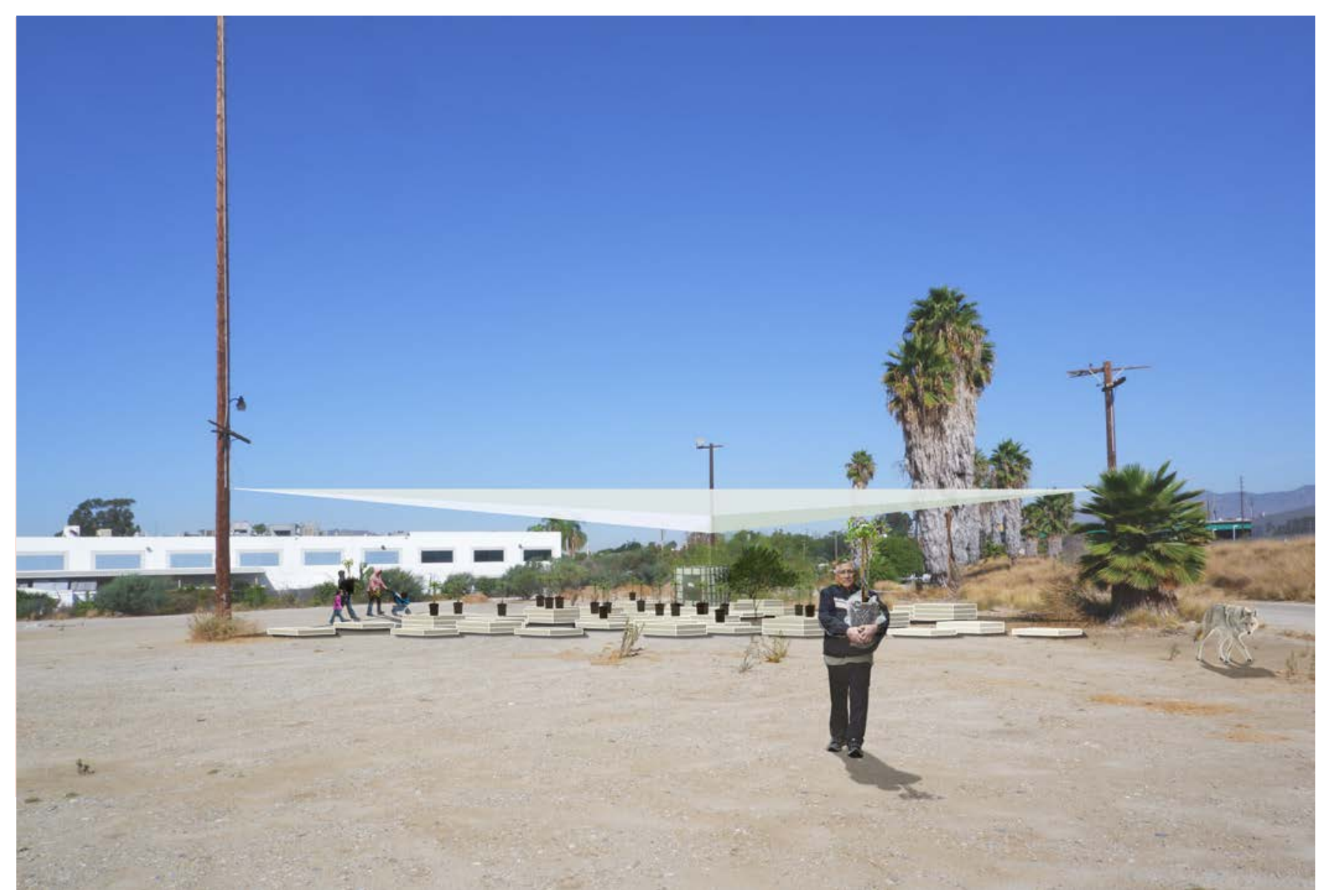

Figure 3. QSU: A tenant takes home a liveoak to plant in their backyard. Image by author.

"Unlike failed radical projects of the past, degrowth does not offer only a new way of realizing humanity's dreams; it changes the dreams themselves."

-Giorgos Kallis, In defense of degrowth

For architecture, the task is not only to change the dreams themselves, but to change which dreams get to become reality. An architecture divorced from the growth machine could center the cultures and needs of poor communities by building power from the grassroots and situating conversations around the future of a neighbourhood amongst its residents. Rather than expansion, the economic engine of communities would be social reproduction: their ability to go on, and to thrive.

A commitment to empowering communities to not only have a say, but control over the future of their nieghborhood, is uncommon in architecture. However, some notable examples from recent years illustrate the potential of practicing degrowth through design today. Chicago's Sweet Water Foundation hosts the Thought Barn, a community-built commons within a community farm that was installed on an empty lot. Sweet Water Foundation's 'by the community, for the community' ethic democratizes design and draws on the existing knowledge about community needs from the community itself. In Portland, City Repair Project empowers community members to shape their own built environment through community permaculture and street painting projects. In both examples, community build days create powerful experiences of cooperation amongst neighbors as they work together to effect material improvements to their neighborhoods, often quite literally putting down roots.

In Detroit, A(n) Office transformed a foreclosed home into a community arts venue. Their project, House Opera / Opera House, not only provided a space for the community to gather, but, by operating outside of the speculative real estate market, gave the designers space to explore a rich conceptual project that engages the relationship between form and performance. As this project demonstrates, a degrowth economy would make architecture a more creative practice. With a turn 
away from the drive for productivity and service provision, the work of architects could be more contemplative, thoughtful, and slow. Theaster Gates' Dorchester Projects are another example of this approach: creating community spaces in a series of foreclosed homes, the project shifts the subject of architecture from the abstract buyer of a house built on speculation, to the collective subject-the community - that lives alongside the built environment of their neighborhood.

My collective, OOLA, completed a proposal in 2019 that demonstrates an active attempt to slow growth in today's economy. We took as our subject the coast live oak, or Quercus agrifolia as it's known in Latin. The project, Quercus Supply, UItd. (QSU) is inspired by Ordinance 177404 of the Los Angeles Municipal Code, which protects the live oak in the face of real estate development, prohibiting the tree's removal once established. The ordinance was introduced in 1980 to ensure that several California native tree species can continue to thrive in their native habitat even as urban land is increasingly commodified and subject to real estate speculation. QSU is a proposal for a pirate nursery for 100 live oaks in the rapidly gentrifying working class neighborhoods of Northeast Los Angeles. Members of the community would be invited to visit the site and take home a tree. As the trees mature, the community gains protections against a system that profits off of their displacement. The trees symbolize the community's fight for public housing, universal rent control, stronger tenant protections, and a right to the city.

While an architecture practice that promotes ecological and social longevity is incompatible with today's political economy, ushering in an alternative future and an alternative economy is crucial to practicing truly sustainable design. 


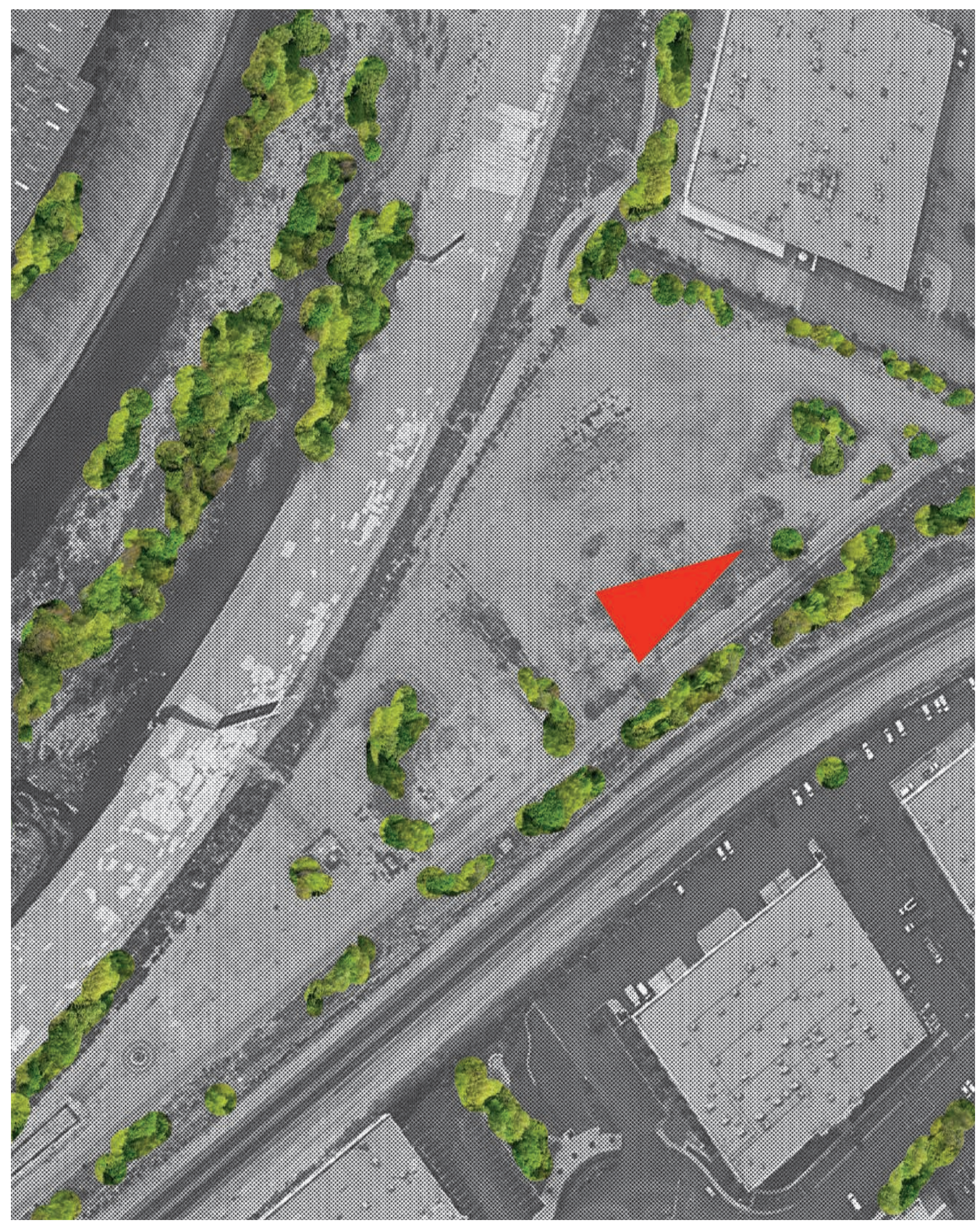

Figure 4. QSU: The site plan of the pirate nursery reveals an ecological occupation of the gentrifying neighborhood around the project's site. Image by author. 


\section{ENDNOTES}

1. Dennis Meadows, Donella Meadows, Jørgen Randers, and William W. Behrens III, The Limits to Growth, (New York: Universe Books, 1972).

2. Kathy Sessions, "Products of the 1992 Earth Summit." US Environmental Protection Agency, October 7, 2016. https://archive.epa.gov/epa/aboutepa/ products-1992-earth-summit.html.

3. Sam Bliss, "Jevons Paradox." Uneven Earth, June 16, 2020. https://unevenearth. org/2020/06/jevons-paradox/.

4. Giacomo d'Alisa, Federico Demaria, and Giorgos Kallis, Eds. Degrowth: A Vocabulary for a New Era (New York: Routledge, 2015).

5. Giorgos Kallis, In defense of degrowth: Opinions and Minifestoes, ed. Aaron Vansintjan (Brussels: Uneven Earth Press, 2017), 188.

6. Samuel Stein, Capital City: Gentrification and the Real Estate State (New York: Verso Books, 2019)

7. Los Angeles Tenants Union, "People's Housing Plan," in L.A. Tenants Union Tenant Handbook, vol I. (2018): 56 